\title{
O jogo com a ambivalência na
}

\section{Tropicália}

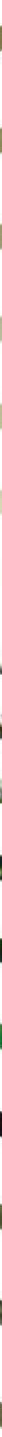

\section{Celso F. Favaretto}

Doutor em Filosofia pela Universidade de São Paulo (USP).

Professor dos Programas de Pós-graduação em Filosofia e em

Educação da USP. Autor, entre outros livros, de $A$ invenção de Hélio Oiticica. 2. reimp. São Paulo: Edusp, 2015. cffavare@usp.br 


\title{
O jogo com a ambivalência na Tropicália
}

Playing with ambivalence in Tropicália

\author{
Celso F. Favaretto
}

\section{RESUMO}

A ambivalência é categoria fundante nas proposições artísticas e nos textos teóricos e críticos de Hélio Oiticica, desde a teoria do parangolé até as manifestações ambientais e seus desenvolvimentos, explicitada exemplarmente na concepção do projeto ambiental Tropicália e nas relações que estabeleceu com a produção do grupo baiano de música popular. Referida também às reelaborações da antropofagia de Oswald de Andrade, a ambivalência é procedimento crítico que presidiu aos processos de criação e à dimensão política de um conjunto significativo de atividades surgidas simultaneamente nos anos 1967-68, que definiram uma posição específica, divergente, quanto às relações entre estética e política evidenciadas na década de 60, questionando as oposições em conflito, então fixadas, entre inconformismo artístico e inconformismo social.

PALAVRAS-CHAVE: crítica; cultura; política.

\begin{abstract}
Ambivalence is a seminal category in Hélio Oiticica's artistic proposals and theoretical texts, since the theory of the parangole until the ambiental manifestations and their developments, made perfectly explicit in the ambiental project Tropicália, and in the relationships he established with the production of the group of popular music from Bahia. Ambivalence is also a critical procedure that refers to the elaborations of Oswald de Andrade's antropophagy and that guided the creative processes and the political dimension of a significative set of activities that emerged simultaneously in the years 1967-68, and that defined a specific position, dissonant in regard to the most evident relationships between aesthetics and politics of the 1960s, questioning the then fixed conflitous opposition between artistic and social inconformism.
\end{abstract}

KEYWORDS: criticismo; culture; politics.

Naquele tempo, tratava-se de propor a arte como modalidade de intervenção na realidade como um todo, ainda que especificamente em alguns de seus aspectos, no sistema de produção cultural e de comunicação, como nas práticas tropicalistas, por exemplo. Tratava-se de fazer a crítica dos lugares institucionalizados de evidenciação e de circulação da arte. Uma arte da ação, de convite, exigência ou imposição de participação, que seria irrecuperável pelo princípio da representação, concebia experiências que implicavam o coletivo, no modo de se apresentar e na significação, visando quase sempre a uma eficácia imediata, e mais, a uma eficácia simbólica. Essas experiências configuravam novos modos de sentir, de relacionar-se, de agir socialmente, com que pretendiam induzir novas formas de subjetividade política, pelo en- 
tendimento que faziam da fusão da arte com a vida. Tempo das ilusões revolucionárias e das mudanças dos comportamentos; tempo das promessas da emancipação. As tendências mais significativas da arte brasileira dos anos 60, algumas advindas já dos 50, estiveram comprometidas com o imperativo modernista da emancipação; as diferenças entre os projetos dependiam da maneira como compreendiam a imbricação de arte e política, ao articularem teorias e práticas às exigências da, assim chamada, realidade brasileira, que se impunham como necessidade.

Considerando que "as práticas artísticas são 'maneiras de fazer' que intervêm na distribuição geral das maneiras de fazer e nas relações com maneiras de ser e formas de visibilidade" ${ }^{\prime 1}$, tratava-se então de inventar proposições, soluções imaginativas, que por uma ação que visava a resultados esperados a conscientização por exemplo -, deveriam distender as formas da experiência política, como a sempre sonhada pela arte: definição de um lugar de fala, inauguração de um tempo de promessas. Como diz Foucault, conceber a vida como arte implica a constituição de modos de existência, de estilos de vida, que relevam da estética e da política, pois ambas das dimensões humanas postulam regras, ainda que facultativas, para o que há para se fazer, para o que se faz e para o que pode ser feito.2 Imbricamento, portanto, de ética e estética, como queriam os artistas dos 60, visionários, que viam nesse modo de generalização da arte a possibilidade de reinvenção da política. Esse imbricamento, como se sabe, princípio e procedimento modernos, implicou e implica ainda uma intervenção no próprio coração do ato artístico: o novo, o que diferencia e abre o vulto da significação, é ruptura, abolição da representação, da forma eleita, inventor da vida nova. Busca política, isto é, busca do que é "comum", procura "das reconfigurações do sensível comum". Algo que remete, talvez, ao que Deleuze denomina enunciação coletiva; a fraturas que Rancière entende como contribuição "para a formação de coletivos de enunciação que repõem em questão a distribuição dos papéis, dos territórios e das linguagens [...] desses sujeitos políticos que recolocam em causa a partilha já dada do sensível". ${ }^{3}$ A intervenção artística deriva, assim, dos modos específicos do sensível com que se apresentam os produtos artísticos, sendo aí que se operam as transformações estéticas que podem fazer o político repercutir sensivelmente.

\section{Imaginários da participação}

Embora às vezes ingênuos, quando pensados retrospectivamente, contudo não no seu surgimento, os projetos e ações das artes dos anos 60 - enquanto imaginavam, um modo solidário de vida social, alegorizadas em suas experiências -, consideravam que as ações derivadas das propostas e programas eram já agentes efetivos, de uma maneira ou outra, de transformação das relações intersubjetivas e coletivas. Acreditava-se quase sempre no valor simbólico das ações, na força do instante e do gesto. Ora, estes atos eram produzidos. Substituía-se o mito da "criação artística" pela ideia de que a invenção é "trabalho", é "fabricação". Considerava-se, assim, que a arte realiza o mesmo

${ }^{1}$ RANCIÈRE, Jacques. A partilha do sensível. São Paulo: Editora 34, 2005, p. 13.

2 Ver DELEUZE, Gilles. Conversações. São Paulo: Editora 34, 1992, p. 119.

${ }^{3}$ RANCIÈRE, Jacques, op. cit., p. 60 e 61. 
princípio do trabalho - a "transformação do pensamento em experiência sensível da comunidade". ${ }^{4}$

Tome-se, por ser exemplar, a maneira como Oiticica propôs a participação coletiva. A sua proposição de antiarte ambiental, além de conceito mobilizador para conjugar a reversão artística e o interesse político, enfim, as dimensões ética e estética, a superação da arte, a renovação da sensibilidade e a participação, implicava o redimensionamento cultural dos protagonistas das ações. As proposições visavam a liberar as atividades do ilusionismo, para que as ações funcionassem como intervenção nos debates daquele tempo. As propostas estéticas não se desligavam da intervenção cultural. Pois, para ele, o campo de ação de sua atividade não se reduzia à crítica do sistema da arte: inscrevia-se como uma atividade coletiva, visionária, em que se interceptavam a produção de novas subjetividades e a significação social das ações. Como Oiticica dizia, não visava com a antiarte à criação de um "mundo estético", pela aplicação de novas estruturas artísticas ao cotidiano; nem simplesmente diluir as estruturas no cotidiano, mas, acima de tudo, transformar os participantes "proporcionando-lhes proposições abertas ao seu exercício imaginativo", de modo a torná-lo "objetivo em seu comportamento ético-social". ${ }^{5}$ Tratava-se, portanto, de outra inscrição do estético: o artista como motivador da criação; a arte como intervenção cultural.

O imaginário que conduzia o experimental de Oiticica é aquele que se interessa pela função simbólica das atividades - o que implica a suplantação da imaginação pessoal em favor de um imaginativo coletivo - e não pelos simbolismos da arte. O requisito para que isso se cumpra é que as atividades, as ações, devem supor uma adequada perspectiva crítica para a identificação das práticas culturais com efetivo poder de transgressão - o que, por sua vez, provém da confrontação dos participantes com as situações. Inconformismo estético e inconformismo social coincidem na conexão de individual e coletivo. A circularidade entre experiência pessoal e experiência artística atinge outra ordem do simbólico, redefinindo o estético pelo deslocamento social da atividade artística.

As relações entre inconformismo estético e inconformismo social foram acirradas e radicalizadas desde o início dos anos 60, compondo estratégias artístico-culturais, políticas, em que o que se visava era resolver ou propor soluções para o tensionamento dessas dimensões, de modo que as proposições artísticas se transformavam em estratégias políticas. Na verdade, desde o modernismo tais relações foram tematizadas, nem sempre compondo projetos transformadores. Por exemplo, a exploração do encontro cultural, na antropofagia e nas proposições de Mário de Andrade, não efetivaram projetos. Nem mesmo a preocupação social na literatura nordestina de Graciliano, Jorge Amado, Lins do Rego e outros compuseram qualquer estratégia específica. Mas, de qualquer maneira, enfatizavam o grande imperativo modernista, mais ou menos nacionalista, conforme o caso, de conhecer o Brasil, de inventar o Brasil.

\footnotetext{
${ }^{4}$ Idem, ibidem, p. 67.

${ }_{5}^{5}$ OITICICA, Hélio. Aspiro ao grande labirinto. Rio de Janeiro: Rocco, 1986, p. 77.
} 
Nos anos 50, quando se desenvolve o processo de modernização estrutural do país e são implementadas ações efetivas de realização daquele imperativo moderno, isto é, quando a modernidade começa a chegar de vez ao país, a preocupação temática desloca-se para projetos e estratégias específicas, de maneira que o tensionamento das duas dimensões já se torna mais acentuado e mesmo radicalizado, especialmente centrado no domínio das formas, isto é, das proposições estéticas que, nem sempre se referindo ao social e ao político, supunham-nas contudo intrínsecas à dimensão estética. Entretanto, no final da década manifesta-se um conflito aberto entre concepções e estratégias artísticas/culturais em torno da articulação política que tinha em vista contribuir para com a emancipação social, pensar o desajuste, a dominação etc. Bienais de São Paulo, Teatro de Arena, Teatro Oficina, Cinema Novo, Bossa Nova, Abstração Geométrica, Concretismo, Neoconcretismo dão a cor das proposições que ora se interceptavam ora se polarizavam. Da maior importância nesse período conturbado politicamente, do suicídio de Getúlio em 1954 à renúncia de Jânio Quadros em 1961, foi o adensamento dos debates em torno desse assunto, sendo que é preciso destacar a ação do Iseb (Instituto Superior de Estudos Brasileiros), fundado em 1955 no governo de Café Filho, como braço intelectual para a formulação de políticas de desenvolvimento do país, responsável pela formação de quadros no meio artístico-cultural que viriam a ser decisivos na virada da década para a radicalização que tomava fôlego e se explicita claramente a partir da posse de João Goulart, com a imediata proposição de rumos que tendiam às reformas necessárias, da política à agrária, bancária, fiscal etc., e de reproposição das relações com o capital internacional aqui atuante de forma decisiva nas diretrizes econômicas e políticas.

Assim, é preciso, ainda que brevemente, indicar posições hegemônicas no período para se entender a organicidade dos desenvolvimentos das relações entre arte e política, dos projetos e estratégias compostas para dar conta da desigualdade, da dependência do desajuste brasileiro, do desejo nacionalista de conhecer e transformar a realidade brasileira, de propor soluções que fossem produtivas para as mencionadas relações entre inconformismo estético e inconformismo social. Isso requer uma reflexão sobre o que Mário Pedrosa entendeu, em 1959, como "condenação ao moderno" ao se referir à "fatalidade mesma de nossa formação". ${ }^{6}$ Isso requereria uma exploração da ideia de que a construção desse país moderno implicava, nas artes e na cultura, a consideração de um "sentido de construção", para usar a expressão de Hélio Oiticica, como modo não só prioritário, como adequado e mesmo consentâneo a certas imagens do Brasil articuladas desde a década de 20 a partir de dados etnológicos e antropológicos que justificariam desde o modernismo a direção construtivista como aquela de que o país necessitava.

Das proposições do CPC (Centro Popular de Cultura) da UNE (União Nacional dos Estudantes), como emblemáticas de uma forma de radicalização do social e do político nas artes, até as tropicalistas do final da década, todas,

${ }^{6}$ PEDROSA, Mário. Brasília, a cidade nova. In: AMARAL, Aracy (org.). Dos murais de Portinari aos espaços de Brasília. São Paulo: Perspectiva, 1981, p. 347. 
em sua diversidade e mesmo em desacordo, manifestavam uma unidade de ação sintomática. Só para se ter uma ideia do que é preciso pensar quanto às variadas estratégias que provinham da intersecção do estético com o político, basta relembrar produções mais significativas que apareceram no incrível ano de 1967: Terra em transe, de Glauber Rocha, a encenação de $O$ rei da vela, pelo Teatro Oficina de José Celso, de Arena conta Tiradentes, no Teatro de Arena de Augusto Boal, o Tropicalismo do grupo baiano, a exposição Nova Objetividade Brasileira, onde aparece Tropicália, a emblemática manifestação ambiental de Hélio Oiticica, os livros PanAmérica, de José Agrippino de Paula, Quarup, de Antonio Callado, Pessach: a travessia, de Carlos Heitor Cony - a que se deve acrescentar, pela sua importância, o filme O bandido da luz vermelha, de Rogério Sganzerla, de 1968. Nestas obras, desdobravam-se proposições que articulavam, em suas particularidades, os signos que vinham se disseminando nas tematizações que fixavam perspectivas para fazer face à situação complexa e tensa em que se compunham os cálculos do regime militar, o resgate das culturas populares, a assimilação de todo tipo de modelos e processos da indústria cultural, cujo desenvolvimento disparava, com penetração nunca vista no país em todas as camadas sociais, manifestando poder e informação - e, simultaneamente, capacidade de diluição - de todo tipo de referências culturais e de técnicas modernizadores com que respondia ao desejo crescente de superação ou apagamento das marcas do subdesenvolvimento.

\section{A virada tropicalista}

Dentre as proposições que mais exploraram a convivência de elementos culturais e artísticos disparatados, sem dúvida foi a atividade tropicalista que mais eficientemente propôs uma via que tinha a ver com o desejo de modernização, com a realização do imperativo moderno de realizar a condenação ao moderno, de tratar a desigualdade, a dependência, os desajustes, as contradições de um modo cuja criticidade alterava os termos em que estavam postas as discussões desde os anos 50, reativando e repensando indicações da antropofagia oswaldiana.

As estratégias visando a compor um trabalho de resistência à ditadura eram marcadas pela ambivalência, derivada da articulação por justaposição de materiais de proveniência diversas, sincréticos, mobilizando nas composições uma atitude de fuga das polarizações, estéticas e ideológicas, para enfrentar as indeterminações do que Hélio Oiticica chamou de "Brasil diarreia", e Décio Pignatari e depois Gil e Torquato, de "geleia geral brasileira". A rememoração dessa atitude crítica produzida nas canções e outras ações tropicalistas, o procedimento crítico que faz da ambivalência uma técnica estético-política, isso está exposto de forma incisiva em alguns textos de Hélio Oiticica: em "A trama da terra que treme: o sentido de vanguarda do grupo baiano" $(1968)^{7}$, em “Brasil diarreia"(1970)8 e em “Experimentar o experimental"(1972). ${ }^{9}$

${ }^{7}$ OITICICA, Hélio. A trama da terra que treme: o sentido de vanguarda do grupo baiano. Correio da Manhã, Rio de Janeiro, 24 nov. 1968.

${ }^{8}$ Idem, Brasil diarreia. In: GULLAR, Ferreira (org.). Arte brasileira hoje. Rio de Janeiro: Paz e Terra, 1973.

${ }^{9}$ Idem, Experimentar o experimental. In: SALOMÃO, Waly e NETO, Torquato (coordenação e organização). Navilouca. Rio de Janeiro: Gernasa, 1974. 
É preciso entender que uma posição crítica implica inevitáveis "ambivalências", pois "pensar em termos absolutos é cair em erro constantemente - envelhecer fatalmente: conduzir-se a uma posição conservadora (conformismos; paternalismos, etc); o que não significa que não se deva optar com firmeza: a dificuldade de uma opção forte é sempre a de assumir as ambivalências e destrinchar pedaço por pedaço cada problema" [...] "entender e assumir todo esse fenômeno, que nada deva excluir dessa "posta em questão": a multivalência dos elementos "culturais" imediatos [...] reconhecer que para se superar uma condição provinciana estagnatória, esses termos devem ser colocados universalmente, isto é, devem propor questões essenciais ao fenômeno construtivo do Brasil como um todo, no mundo [...] Nossos movimentos positivos parecem definir-se como, para que se construam, uma cultura de exportação: anular a condição colonialista é assumir e deglutir os valores positivos dados por essa condição e não evitá-los como se fossem uma miragem [...] assumir e deglutir a superficialidade e a mobilidade dessa "cultura", é dar um passo bem grande - construir - ao contrário de uma posição conformista, que se baseie sempre em valores gerais absolutos: essa posição construtiva surge de uma ambivalência crítica". "A formação brasileira [...] é de falta de caráter incrível: diarréica; quem quiser construir [...] tem que ver isso e dissecar as tripas dessa diarreia - mergulhar na merda" [...] a condição brasileira, mais do que simplesmente marginal dentro do mundo, é subterrânea, isto é, tende e deve erguer-se como algo específico ainda em formação [...]: assume toda a condição de subdesenvolvimento, mas não como uma "conservação desse subdesenvolvimento", e sim como uma... "consciência para vencer a superparanoia, repressão, impotência" brasileiras. O que mais dilui hoje no contexto brasileiro é justamente essa falta de coerência crítica que gera a tal conviconivência; a reação cultural, que tende a estagnar e se tornar oficial. ${ }^{10}$

Nestes textos e em outros aparecem claramente as referências ao modo de Oiticica entender a relação entre atividades críticas de vanguarda e consumo: "o experimental assume o consumo sem ser consumismo", pois para ele "fugir ao consumo" não é "uma posição objetiva [...] mais certo é sem dúvida consumir o consumo como parte dessa linguagem". ${ }^{11}$ Proposição polêmica, que esteve na base das críticas mais acerbas feitas aos tropicalistas. A ambivalência é gerada no procedimento de justaposição dos materiais arcaicos e modernos, cultos e populares, experimentais e da cultura de massa, constantes da experiência brasileira, que por efeitos de humor, paródia e alegorização, são deslocados, assim criticados. A frase de Oiticica, em sua concisa concentração conceitual, indicava a relação tensa entre vanguarda e comunicação, vanguarda e mercado, não como uma composição oportunista e conformista, como foi o acentuado em algumas críticas. Tratava-se de um descentramento das questões em debate nas atividades artísticas e críticas, fazendo uma reavaliação dos fracassos ou das inadequações dos projetos e estratégias culturais que visavam à politização das ações. Uma reavaliação dos efeitos e eficácia política dessas ações implicava inevitavelmente o questionamento dos modos de expressão artística e do papel sócio-histórico da arte. De modo especial, pensando-se na questão candente na época, a da participação, do sentido éticopolítico das atividades, tratava-se de propor atividades pensadas como intervenções no sistema da arte.

\footnotetext{
${ }^{10}$ Idem, Brasil diarreia, op. cit., p. 150 e 151.

${ }_{11}^{1}$ Idem, Experimentar o experimental, op. cit., p. 6.
} 
Nessas atividades, deslocava-se a ênfase nos simbolismos da arte para a função simbólica das atividades com vistas à configuração de um imaginário coletivo. Isso se cumpriria quando a criticidade das ações derivasse da identificação, da escolha certeira, das práticas culturais supostas com poder de transgressão - não pela simples figuração das indeterminações e conflitos sociais ou pela denúncia dos desajustes da realidade brasileira e exortação a ações transformadoras, mas pela confrontação dos participantes com situações que pudessem provocar mudanças de comportamento, pela renovação da sensibilidade, desterritorialização dos imaginários vigentes da participação pela arte, coletivizando as ações. Da maior importância foi a atitude de deslocar os modos vigentes de interesse pelo coletivo, de expressão do inconformismo social na experimentação artística, pelo ultrapassamento do mero interesse pelas mitologias, valores e formas de expressão das experiências populares.

O interesse de Oiticica por práticas populares não implicava recurso à valorização, dada naquele momento, à cultura popular com ênfase em "raízes populares". O destaque conferido à Mangueira, ao samba, à construtividade popular, derivam da sua concepção de antiarte ambiental, da sua experiência da marginalidade. Mantendo-se afastado dos projetos culturais que figuravam a "realidade nacional", como etapa da ação política que reagia à dominação do imperialismo e do regime militar, Oiticica respondeu à sua maneira aos apelos dessa posição. A sua marginalidade foi vivida, pois é o ponto em que se desfaz a contradição do inconformismo estético e do inconformismo social. Para ele, a arte tem sempre função política, contanto que isso não seja um "alvo especial", mas sim "um elemento", porque, "se a atividade é não repressiva, será política automaticamente". ${ }^{12}$ Arte e política são práticas convergentes, mas que não se confundem, sob pena de se promover a estetização da política.

\section{Ética e estética: a explosão do óbvio}

Com Tropicália Oiticica objetiva o "sentido ético" como prática cultural, determinando a posição crítica que o distinguiu, pela coerência, radicalidade e lucidez, das demais propostas em desenvolvimento na vanguarda brasileira. Em Tropicália, a "objetivação de uma imagem brasileira" não se faz pela figuração de uma realidade como totalidade sem fissuras, e sim pela devoração das imagens conflitantes que encenam uma cultura brasileira. Esta devoração se atribui aos participantes: apropriando-se dos elementos disparatados, justapostos, que formam uma "síntese imagética" - na verdade uma mistura de imagens, linguagens e referências -, os participantes agem nesse sistema conjuntivo e ambivalente, produzindo a evidenciação do processo de constituição das contradições enunciadas. O objetivo é provocar a explosão do óbvio por efeito da participação. Conjugando estrutura e fantasia, no ambiente tramamse intervenções que vão estendendo as proposições. Com isso, tudo o que é traço cultural é ressignificado. Alheia ao exclusivismo da experimentação ou da expressão de conteúdos do nacional-popular, Tropicália conjuga experimentalismo e crítica. Para Oiticica, ela é produção em que as imagens "não podem

${ }^{12}$ Idem, apud AYALA, Walmir (org.). A criação plástica em questão. Petrópolis: Vozes, 1970, p. 166. 
ser consumidas, não podem ser apropriadas, diluídas ou usadas para intenções comerciais ou chauvinistas" ${ }^{13}$

Tropicália define uma linguagem de resistência à diluição: assumir uma posição crítica, diz Oiticica, é enfrentar a "convi-conivência", essa doença tipicamente brasileira, misto de conservação, diluição e culpabilidade, que concentra os "hábitos inerentes à sociedade brasileira": cinismo, hipocrisia e ignorância. ${ }^{14}$ Essa "posição crítica universal permanente", a que denominou "o experimental", possibilitou-lhe interferir na vanguarda brasileira, enquanto nela encontrou condições para desenvolver projetos coletivos implícitos em seu programa-parangolé.

Não existe "arte experimental", mas o experimental que não só assume a ideia de modernidade e vanguarda, mas também a transformação radical no campo dos conceitos-valores vigentes: é algo que propõe transformações no comportamentocontexto, que deglute e dissolve a convi-conivência. No Brasil, portanto, uma posição crítica universal permanente e o experimental são elementos construtivos. Tudo o mais é diluição na diarreia. ${ }^{15}$

Assim, o alcance crítico que Oiticica atribui à sua posição provém da atitude de desestabilização do experimentalismo e das interpretações culturais hegemônicas. Ao insistir na "urgência da colocação de valores num contexto universal", para "superar uma condição provinciana estagnatória"', rompe com os debates que monopolizavam as práticas artísticas e culturais, radicalizando-os. Com Tropicália, o projeto e a teorização, Oiticica, juntamente com as demais produções identificadas como "tropicalistas", evidenciou o conflito das interpretações do Brasil sem apresentar um projeto definido de superação dos antagonismos. Expondo a indeterminação da história e das linguagens, devorando-as, todas ressituaram os mitos da cultura urbano-industrial, misturando elementos arcaicos e modernos, explícitos ou recalcados, ressaltando os limites das polarizações ideológicas no debate cultural em curso.

\section{HO e o grupo baiano: da Tropicália ao tropicalismo}

É nessa direção que Oiticica destaca a importância da produção do grupo baiano, identificando-a às propostas e à linguagem de seu programa ambiental. Para ele, ambas articulam o experimentalismo construtivista e o comportamental; nelas a participação é constitutiva da produção, e a crítica, efeito da abertura estrutural. Para ele, o caráter revolucionário implícito nas suas criações e posições deve-se à não distinção entre experimentalismo e crítica da cultura; à ausência de privilégios entre posições discrepantes, quando se trata de "constatar um estado geral cultural" e nele intervir; e, finalmente, à

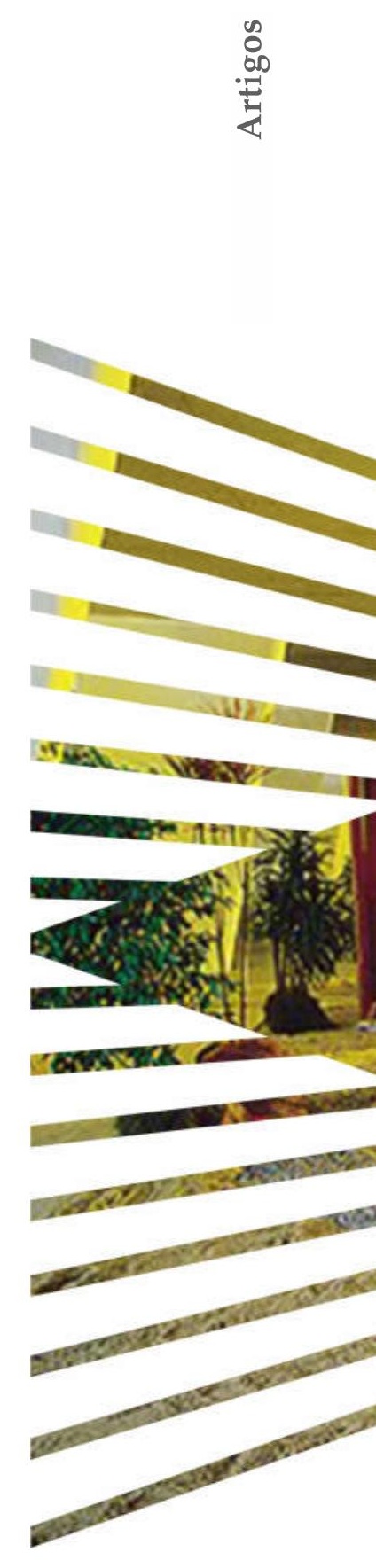

\footnotetext{
${ }^{13}$ OITICICA, Hélio. Aspiro ao grande labirinto, op. cit., encarte.

${ }^{14}$ Cf. idem, Brasil diarreia, op. cit., p.147 e 149.

${ }^{15}$ Idem, ibidem, p. 152.
} 
não distinção entre a repressão da ditadura e setores da crítica e do público de esquerda. ${ }^{16}$

Oiticica identifica nos músicos a mesma tônica de suas manifestações ambientais: a renovação de comportamentos, de critérios de juízo e a eficácia crítica passam pelo modo de produção, em que se aliam conceitualismo, construtividade e vivência. Ambas as produções originam conjuntos heteróclitos, em que processos artísticos e culturais diversos são justapostos e, efeito da devoração, reduzidos a signos que agenciam ambivalência crítica e exploram a indeterminação do sentido, propondo-se, assim, como ações que exigem dos participantes a produção de significados. Ambas fazem parte do projeto crítico que assume a ambivalência como modo de enfrentar a "diarreia" brasileira. Um simples cotejo entre a estrutura das duas tropicálias, o labirinto de Oiticica e a canção de mesmo nome de Caetano Veloso, evidencia o caráter ambiental e o construtivismo que lhes é comum, ou seja, a coincidência dos modos de operar o experimentalismo conjugado à crítica cultural. A convergência dessas produções pode ser assinalada, por exemplo, na mudança radical da recepção: a transformação do ouvinte e do espectador em protagonistas de ações, que tanto se referem às intervenções implícitas na própria estrutura das obrasacontecimentos, quanto às alusões a outros modos de categorizar e contextualizar as ações.

Dessa maneira, o jogo com a ambivalência difere de algumas críticas surgidas naquele momento que incidiam sobre a ambiguidade das práticas artísticas de vanguarda, particularmente a tropicalista. Por exemplo, aquela que entendia que "progresso técnico e conteúdo social reacionário" poderiam se combinar na experimentação artística de vanguarda, daí admitirem o jogo com o mercado como integrante do processo de produção. ${ }^{17}$ Tal ressalva ao tropicalismo provinha da ideia de que nele o mercado, além de determinante na criação, apenas acentuava as aparências da sociedade, não sendo, assim, crítico. Também exemplar dessa posição é o texto de Augusto Boal constante do folheto de apresentação programa da 1a. . Feira Paulista de Opinião, produzida pelo Teatro de Arena, em que de forma incisiva denunciava a determinação do mercado na produção artística/cultural daquele momento: para ele, o tropicalismo era neorromântico, artisticamente inarticulado, caótico, homeopático, importado e sem clareza política, e que, por isso, ambiguamente, endossava o que criticava. ${ }^{18}$

Como se sabe, os tropicalistas não elidiam essa discussão, tanto no implícito das canções como nas declarações e atitudes; acima de tudo na materialidade da linguagem, do processo construtivo. A colocação do aspecto estético e do aspecto mercadoria no mesmo plano, essa ambivalência, fazia parte da estratégia que dialetizava o sistema da arte, eis a sua aposta. Tal estratégia substituía as formas consagradas de participação - em que frequentemente o político das ações era reduzido pela ênfase no primado dos efeitos imediatos e, em grande parte, emotivos, do poder da denúncia e da exortação - pelo

\footnotetext{
${ }_{16}$ Ver idem, A trama da terra que treme: o sentido de vanguarda do grupo baiano, op. cit.

${ }^{17}$ Ver SCHWARZ, Roberto. Nota sobre vanguarda e conformismo. Teoria e Prática, n. 2, São Paulo, 1967, p. 127.

${ }^{18}$ Ver BOAL, Augusto. O que pensa você do teatro brasileiro? Catálogo da 1ª. Feira Paulista de Opinião (1968). Reproduzido em Arte em Revista, n. 2, São Paulo, 1979, p. 43.
} 
processo de composição que articulava estrutura e comportamento, construtividade e vivência na elaboração crítica que, pela justaposição de elementos discordantes, evidenciava o processo de constituição mesma das contradições enunciadas. Ao invés da crença na eficácia imediata da figuração da realidade brasileira, propunha um deslocamento que, pela devoração das imagens, encenava aspectos emblemáticos da realidade brasileira - como se pode ver, por exemplo, nas canções "Tropicália", "Geleia geral”, "Parque industrial”, "Marginália II", "Enquanto seu lobo não vem" e na manifestação ambiental Tropicália, de Oiticica: um processo conjuntivo e_ambivalente, corrosivo, que vinha da transformação do receptor em ativo decifrador de signos, com que se articula em outro nível de consciência.

Assim, o jogo com a ambivalência, por ser construtivo (construtivista, experimental), nas canções acentua a indeterminação como índice de criticidade que opõe resistência ao consumo das imagens. Daí a radicalidade das músicas tropicalistas e da antiarte de Oiticica quando pensam a simultaneidade de crítica e inserção no mercado. A indistinção entre estética e mercadoria faz parte da sua estratégia de dessacralização para enfrentar a "conviconivência". O consumo era visto como uma das categorias transformadoras, como modo de enfrentar a dissolver as dualidades erigidas como oposições, pela exploração da ambivalência, saindo das oposições - bom gosto e mau gosto, nacional e internacional, cultura superior, culta de massa e cultura popular, vanguarda e comunicação, crítica e conformismo. A desmistificação das relações entre criação e consumo destoava de posições que à esquerda e à direita condenavam o envolvimento comercial das artes, da arte em geral.

$\mathrm{O}$ aspecto comercial e a integração das técnicas modernas nas artes e o conúbio com o sistema de comunicação era tido, geralmente, como submissão às modas. Os novos meios de comunicação, entretanto, não estavam propriamente descartados, pois poderiam servir à disseminação de informações como meio de conscientização. Aos tropicalistas, contudo, não parecia possível apropriar-se desses recursos e ao mesmo tempo preservar uma suposta neutralidade da arte. Assumir a ambivalência era o modo eficaz, ética e esteticamente, de enfrentar a diarreia brasileira.

É possível verificar a eficácia da intervenção tropicalista, e o seu jogo com a ambivalência, lançando a atenção sobre os processos de construção das imagens nas canções, basicamente sobre o procedimento alegórico. As canções tropicalistas resultam de um processo construtivo em que as imagens emergem da justaposição de materiais de procedência diversa, de elementos díspares, provocando um efeito de obscuridade e estranheza. Cenas alusivas, fragmentárias, compostas como alegorias do Brasil, remontavam à persistência dos arcaísmos, das deformações no processo de modernização da sociedade, tal como estão explicitados nas interpretações vigentes no sistema artísticocultural. As canções, individualmente ou em conjunto, quando assim consideradas, configuram, na fulguração de suas imagens, uma situação histórica impossível de ser concretizada com nitidez e que irrompe sob a forma de retorno do recalcado. Assim, as canções geram significações conflitantes com os significados designados como identificadores de uma entidade abstrata, a "realidade brasileira", emblematizados em signos que indiciam "as relíquias do Brasil", como os enunciadas na canção "Geleia geral" de Torquato Neto e Gilberto Gil. Os fatos culturais designados, as formações históricas, os estilos 
artísticos, usos e costumes, são desapropriados de seus valores já fixados como tradição, como identitários, e são transfigurados pela parodização, pelo humor, pela sátira, pelos procedimentos grotescos, pela carnavalização da linguagem, evidenciando sintomas de uma história malformada e que talvez nunca tenha chegado verdadeiramente a ser. A composição de paródia e alegoria, efetivada nas canções tropicalistas, leva adiante um trabalho extremamente importante e inédito, o trabalho de corrosão da cultura instituída em seus diversos matizes. Corrosão do mito das raízes populares, das mitologias da cultura de mercado, a operação desmistificadora efetivada nas canções pode ser entendida como um trabalho crítico, um processo de descolonização e de descentramento cultural.

Artigo recebido em 10 de novembro de 2020. Aprovado em 30 de novembro de 2020. 